\title{
A Collaborative Geospatial Shoreline Inventory Tool to Guide Coastal Development and Habitat Conservation
}

\author{
Diana Mitsova $^{1, *}$, Frank Wissinger ${ }^{2}$, Ann-Margaret Esnard ${ }^{1}$, Ravi Shankar ${ }^{2}$ and Peter Gies ${ }^{1}$ \\ 1 School of Urban and Regional Planning, Florida Atlantic University, 111 E. Las Olas Blvd., \\ Fort Lauderdale, FL 33301, USA; E-Mails: aesnard@ fau.edu (A.-M.E.); pgies@ fau.edu (P.G.) \\ 2 Department of Computer and Electrical Engineering and Computer Science, Florida Atlantic \\ University, 777 Glades Road, Boca Raton, FL 33431, USA, E-Mails: fwissing@fau.edu (F.W.); \\ shankar@fau.edu (R.S.) \\ * Author to whom correspondence should be addressed; E-Mail: dmitsova@fau.edu; \\ Tel.: +1-954-762-5674.
}

Received: 11 March 2013; in revised form: 2 May 2013 / Accepted: 2 May 2013 / Published: 13 May 2013

\begin{abstract}
We are developing a geospatial inventory tool that will guide habitat conservation, restoration and coastal development and benefit several stakeholders who seek mitigation and adaptation strategies to shoreline changes resulting from erosion and sea level rise. The ESRI Geoportal Server, which is a type of web portal used to find and access geospatial information in a central repository, is customized by adding a Geoinventory tool capability that allows any shoreline related data to be searched, displayed and analyzed on a map viewer. Users will be able to select sections of the shoreline and generate statistical reports in the map viewer to allow for comparisons. The tool will also facilitate map-based discussion forums and creation of user groups to encourage citizen participation in decisions regarding shoreline stabilization and restoration, thereby promoting sustainable coastal development.
\end{abstract}

Keywords: participatory GIS; collaborative mapping; ESRI GeoPortal Server; coastal planning; geovisualization 


\section{Introduction}

The network of coastal geospatial data service providers has expanded over the past decade to include, among others, local governments, academic institutions, private companies and non-profit organizations [1]. A multitude of web resources known as web atlases [2], geoportals [1,3], geowebs [4] and other forms of operational tools and geospatial archives have been created to facilitate access to geospatial resources for GIS and non-GIS users and enhance opportunities for collaborative decision-making and governance. The creation and dissemination of customized geo-browsers and other web-based tools and mapping resources have improved access to geospatial data, enabled interactive visualization and communication and, in many ways, facilitated collaborative decision-making, coastal governance and planning [2,5,6].

Recent coastal tool development initiatives highlight the importance of collaborative decision-making and networking. For example, MarineMap (www.marinemap.org) and SeaSketch (www.seasketch.org) are coastal planning web-based tools that provide opportunities for spatial data exploration and simultaneously allow user input, participation and comparison of user-proposed solutions against scientific criteria [7]. Other coastal mapping tools designed specifically to reinforce the participatory component include the Coastwatch project [8] and MARGov (Model of Collaborative Governance for Marine Protected Areas) [9]. Beyond marine and ocean planning, such resources can be particularly useful in the context of disaster management and disaster response [10,11], integrated coastal zone management [12], protection of coastal resources and coastal cultures conservation [13], monitoring and prevention of oil spills [14] and developing conservation design protocols for coastal areas to minimize conflicts between human uses and wildlife habitats [15].

Several state agencies have made important contributions by developing multi-functional online coastal atlases that allow users to assess existing conditions, visualize multiple uses and objectives, identify existing or potential conflicts between proposed uses and design workable alternatives [2]. Examples of coastal atlases include Oregon Coastal Atlas (http://www.coastalatlas.net/); Alaska ShoreZone (http://alaskafisheries.noaa.gov/shorezone/default.htm); British Columbia Pacific Coast Resource Atlas (http://cmnbc.ca/atlas_gallery/pacific-coastalresources-atlas-british-columbia); Washington Coastal Atlas (http://www.ecy.wa.gov/programs/sea/sma/atlas_home.html); Southern California MarineMap Tool (http://marinemap.org/marinemap/); California Ocean Uses Atlas (http://mpa.gov/pdf/helpfulresources/factsheet_atlasdec08.pdf); and California Coastal Atlas (http://californiacoastalatlas.net/). Regional initiatives have also emerged, including MADRONA, Mid-Atlantic marine planner (http://portal.midatlanticocean.org), which engages stakeholders in coastal and marine planning from five states. These tools use software stacks and high performance web frameworks to enhance user interface, facilitate data layer development and publishing, process file tiling and create interactive web-based mapping applications. With these developments, geospatial data previously handled only by GIS users is now available to the larger audience of non-GIS users.

Emerging applications increasingly use various platforms for user-generated content [16]. Known as "volunteered geographic information" [17,18], Web 2.0 [16,17,19] or "crowdsourcing" [10], these platforms have opened numerous possibilities for "a bi-directional collaboration in which users are able to interact with and provide information to central sites and see that information is collated and made available to others" [17] (p. 27). Goodchild [17] pioneered the concept of "volunteered 
geographic information" (VGI) as a new distributed form of data acquisition, which became available with the Web 2.0 service operating environment. VGI assumes that information that originates from a large group of individuals is potentially more complete and accurate than information that originates from a single source [16-18].

Building upon these conceptual frameworks, initiatives and applications, we are developing a geospatial inventory tool that will guide habitat conservation, restoration and coastal development and benefit several stakeholders who seek mitigation and adaptation strategies to shoreline changes resulting from erosion and sea level rise. We use the ESRI Geoportal Server, an open source geospatial resources management software first released by ESRI in 2010. Its latest version 1.2.2, released in July 2012, employs a collection of software modules and components to allow users to search and access geospatial information stored in a central repository [20]. This flexible web-based framework renders itself customizable to display map data and build query functions. Examples of customized geoportals include Geospatial One-Stop (https://explore.data.gov/), USEPA Environmental Dataset Gateway (edg.epa.gov), NOAA National Climatic Data Center (gis.ncdc.noaa.gov), Kentucky Geographic Network (http://kygeonet.ky.gov/) and Montana GIS Portal (gisportal.msl.mt.gov).

In this paper, we begin with a brief description of the pilot study area. We then discuss the process of customization of the ESRI Geoportal server for the purposes of the shoreline inventory and characterization, as well as data and data sources. The subsequent section includes a brief discussion of the intended uses and future add-ons to the tool. We conclude with a summary of the implications of the tool development for coastal and marine planning.

\section{Study Area}

Our pilot study area focused on north Miami-Dade County, which is one of the most densely populated areas in South Florida that is vulnerable to coastal hazards, including erosion, storm damage and sea-level rise. According to the 2010 Census data, the average population density in Miami-Dade is 1,283 persons per square mile, much higher than the national average of 87 persons per square mile and the average for the State of Florida (349 persons per square mile). In the past few decades, a considerable amount of commercial and residential development occurred in the North Miami-Dade shore zone, resulting in some of the highest amounts of taxable value along the coast and the second highest population to shoreline length ratio in the State of Florida [21]. The area is also one of the most vulnerable to hurricane strikes.

Coastal development associated with the growth of the Miami metropolitan area and increasing population densities have altered the natural environment, which was dominated in the past by vast coastal wetlands. Over the years, dredging and filling activities, which began with the construction of the Florida East Coast Railroad at the end of the 19th century, essentially removed large portions of the low coastal wetlands along more than 30 miles of the shoreline bordering Biscayne Bay, Florida [22].

Biscayne Bay estuary located along the lower east coast of Florida extends roughly $56 \mathrm{~km}$ from north to south and covers an area of 570 square kilometers. Under the Florida Aquatic Preserve Act of 1975, the northern part of Biscayne Bay, which extends along the highly urbanized core of the metropolitan area, was declared an Aquatic Preserve. In addition to the major transportation routes and causeways that transect the area, the northern section of Biscayne Bay also harbors a massive seaport 
infrastructure. The intensive coastal development resulted in large segments of concrete bulkheads installed to contain the dredge and fill material. In many locations, including Key Biscayne, the historic wetlands were replaced by artificially created uplands that soon became populated by exotic species, including the invasive Australian Pine (Casuarina equisetifolia) [22]. Additionally, the increase in impervious surfaces, terrain alterations and coastal armoring combined with the extended dry periods were found to affect measured concentrations of pollutants in urban runoff [23].

Figure 1. Location of the study area and extent of existing coastal armoring.

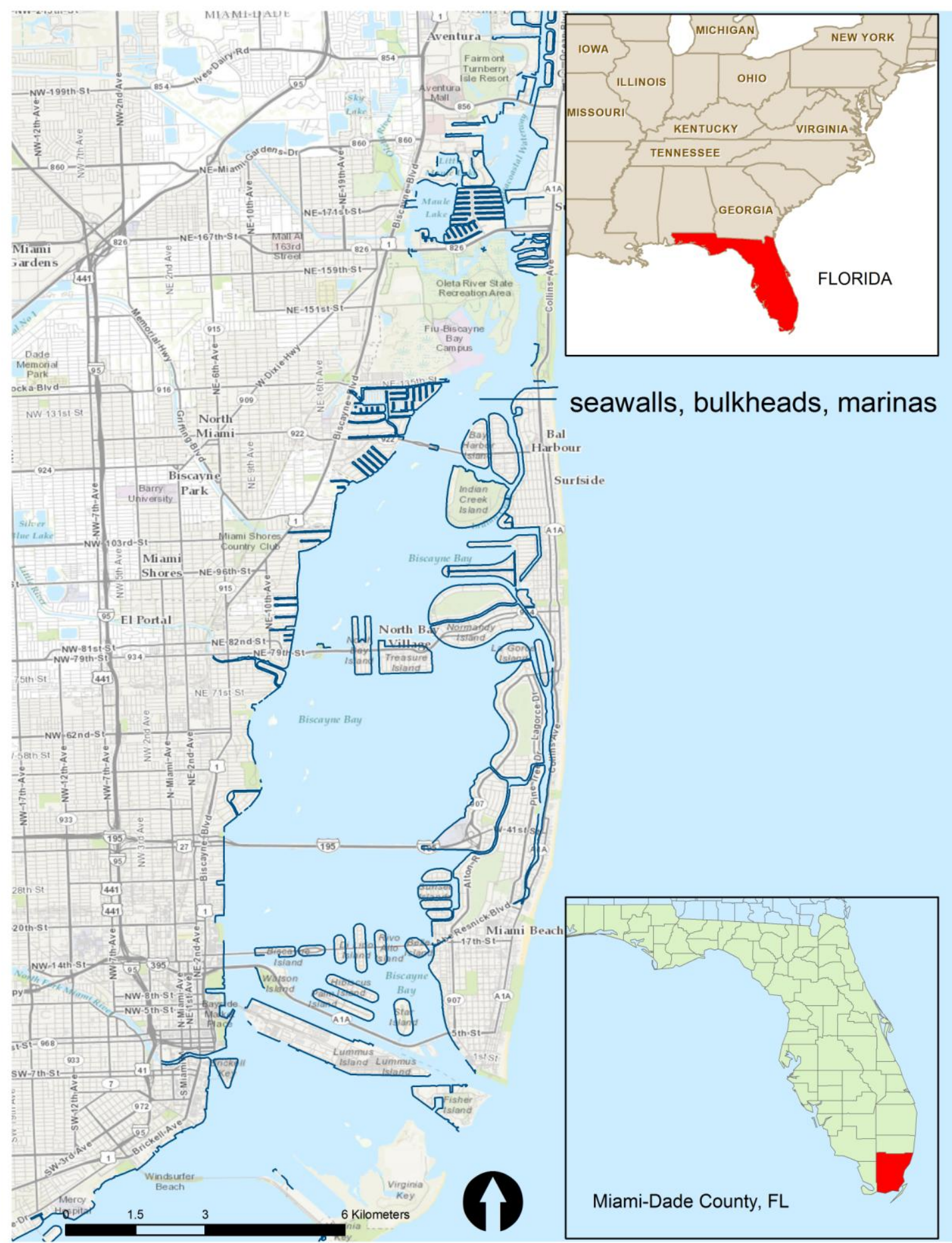


For years, coastal armoring has been the typical response to coastal erosion [24,25]. These structural stabilization options, including seawalls, bulkheads and groins are known to increase downrush and scouring and undermine the structure itself [26]. Coastal armoring can also result in reduced sediment sources along the shore and gradual disappearance of beaches and marshes in front of the structure [24]. In addition, shoreline armoring can affect habitat and water quality and result in ecosystem productivity loss [24]. Figure 1 depicts the extent of shoreline armoring in the northern part of Biscayne Bay. Recognition of the structural and environmental problems created by hardened shoreline defenses led to the implementation of "soft" stabilization approaches focusing on planters, ripraps and breakwaters and replanting the intertidal zone and uplands near the shore [24,25]. As the ecological and economic vitality of the area depends heavily on the health of its coastal and eco-marine systems, Miami-Dade County has taken measures to protect marine and estuarine habitats and reduce erosion. Since the 1990s, the Florida Department of Environmental Protection and the county have undertaken several major initiatives to address the need for recovery and restoration of the lost historic wetlands to the extent possible [22]. Under the provisions of Chapter 24.58 of the Code of Metropolitan Dade County, the Miami-Dade Department for Environmental Resource Management has applied the "concept and/or use of natural vegetation communities on the majority of public owned shorelines in Biscayne Bay and on Miami-Dade's barrier beaches" (MDC, personal communication, 2011). More specifically, the County is in a process of applying riprap revetments/planters in some inshore and beaches/barrier island shores as an alternative to new or replacement seawalls (MDC, personal communication, 2011). These efforts often require stakeholder participation.

Understanding the anticipated impacts and developing response strategies is currently hindered by a lack of an easily accessible way of obtaining multi-attribute characterization data of each segment of the shoreline. The information is available from multiple sources in a variety of spatial resolutions and formats and normally, long processing times are required to derive meaningful summaries and statistics. The shoreline inventory and characterization tool aims to provide additional geospatial resources and facilitate citizen involvement and participation in the ongoing shoreline restoration and stabilization efforts.

\section{Geospatial Shoreline Inventory Tool: Conceptual Framework and Customization Overview}

The standard ESRI Geoportal Server application has been customized to serve the purposes of the shoreline inventory tool. In its original form, the Geoportal server is an open source metadata management tool. It has some functionality in uploading metadata; however, it does not allow for the upload and standard work with GIS shapefiles.

Customizable features and functionality were developed to allow for a wide variety of stakeholders to explore shoreline data, conduct queries and generate summary reports. The shoreline inventory and characterization tool consists of the following components: a customized geoportal server with visualization and analytical tools, geospatial data (e.g., shapefiles and their associated attribute tables), metadata and a general user information blog. This section describes each of these components in detail. Figure 2 displays a conceptual diagram of the main components of the shoreline inventory and characterization tool based on a customized ESRI Geoportal Server. The dashed lines indicate where the customization of the programming code occurred. 
Figure 2. Conceptual diagram of the customized ESRI Geoportal webserver.

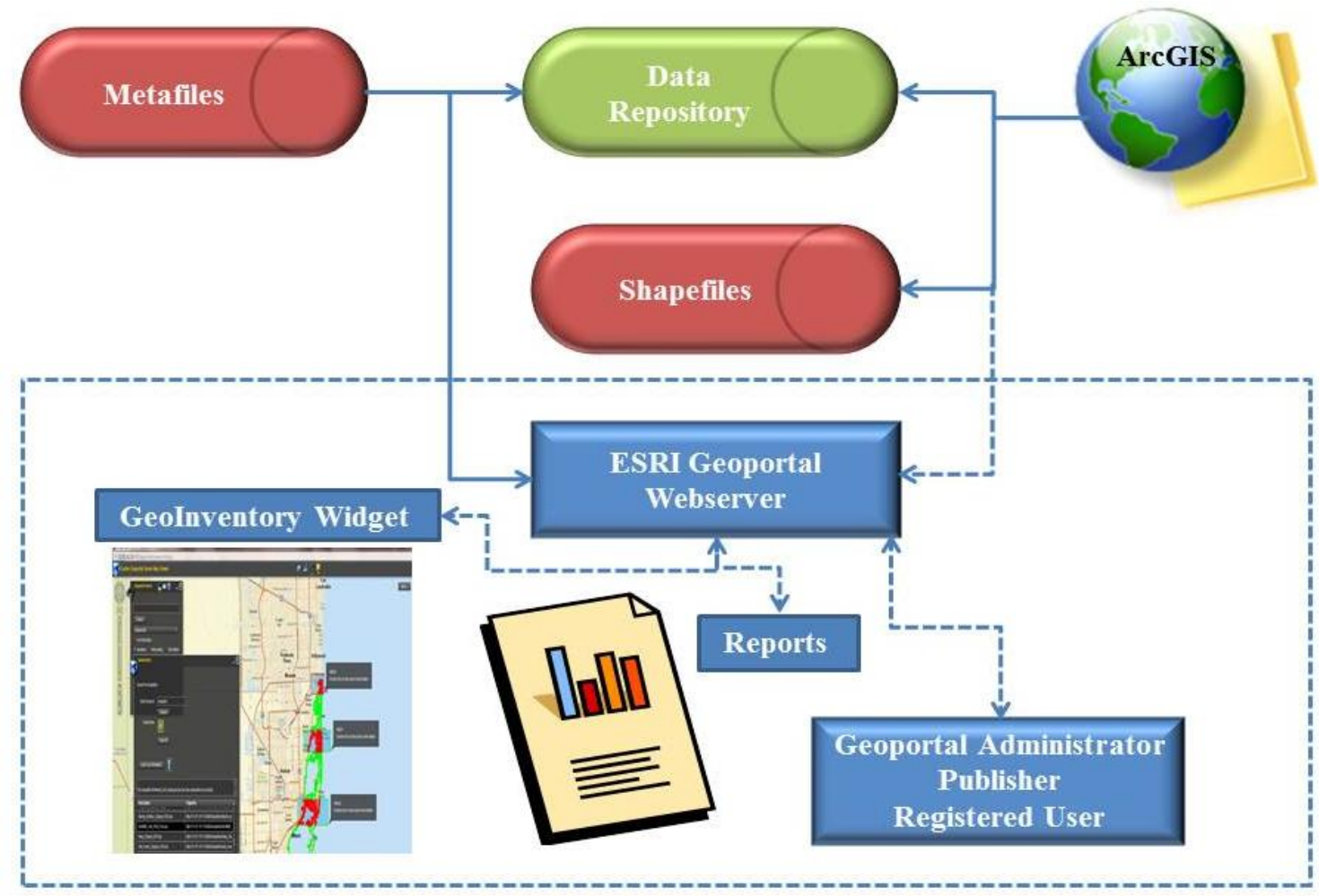

Figure 3. Components of the ESRI Geoportal webserver.

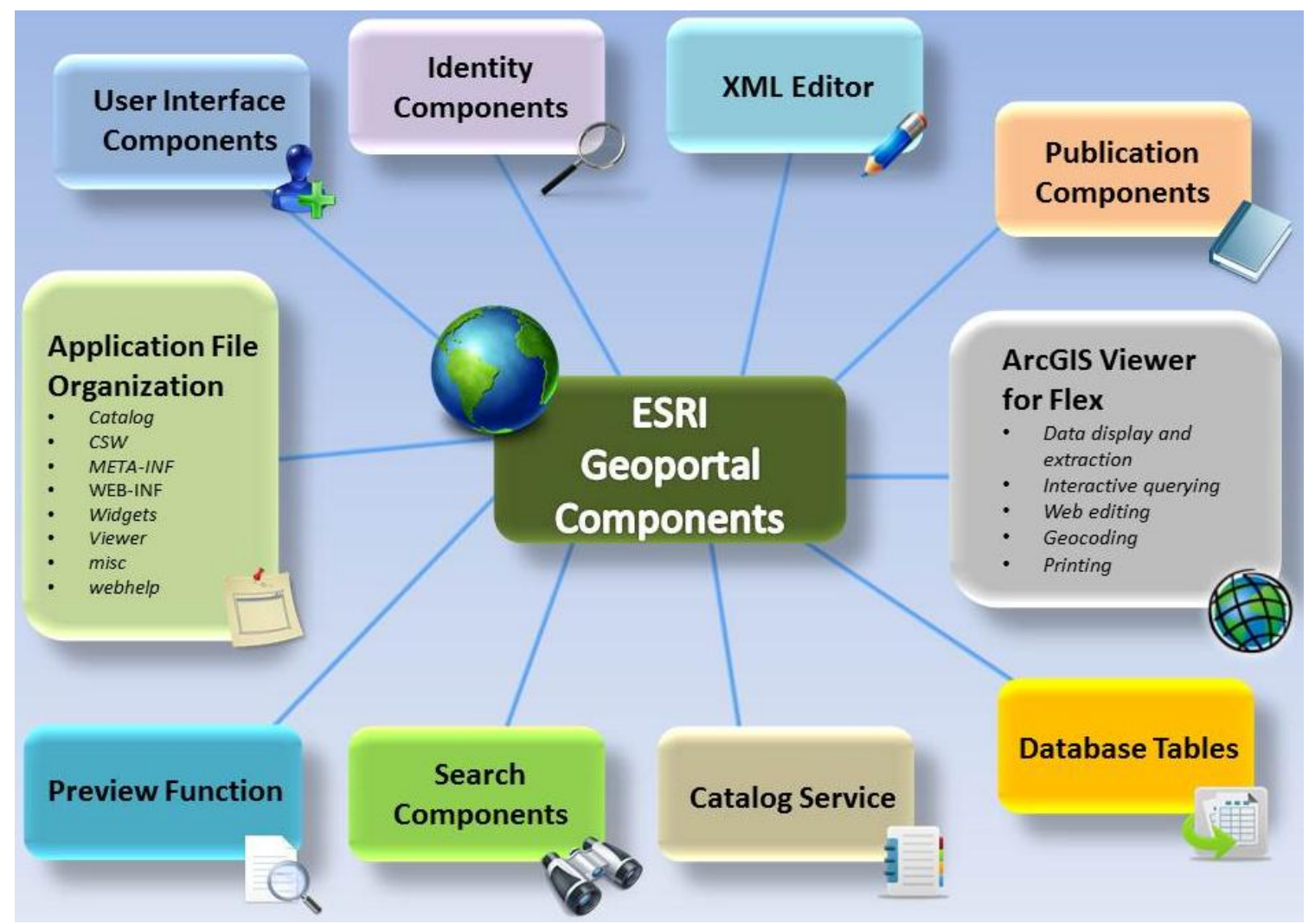

The most commonly used components of the Geoportal (Figure 3) include a user interface, directory access protocols and single sign-on, XML editor, data management and publication 
components, a relational database and a search component for managing requests and parsing responses [20]. The user interface component of the Geoportal relies on JavaServer Faces (JSF) framework to process requests and ensures proper navigation and rule implementation. The identity component is composed of Java-based external directory access protocol and sign-on information stored in an identity folder that allows authentication of users and groups [20]. The database and publication components define the data structure as it pertains to a relational database management system and specifies database uses and permissions. The Geoportal XML editor supports advanced functionalities in metadata editing. Geoportal resources are published through the Catalog Service for the Web (CS-W) where searchable elements are extracted through a search engine component [20].

\subsection{Customization of ESRI Geoportal Webserver Components: Overview}

Our unique customization resulted in functionalities built into ArcGIS Viewer for Flex to allow users to upload geospatial data, explore spatial data and derive summary statistics. The following components of the ESRI Geoportal webserver were customized by modifying programming code blocks: User Interface Components, Lightweight Directory Access Protocol (LDAP), Publication Components, ArcGIS Viewer for Flex, Catalog Service, Database Tables and Search Components. A detailed description of the code modification and customization is provided in the Results section of this manuscript.

As part of this pilot project, GeoInventory and query tools were built within ArcGIS Viewer for Flex. A customized widget named Geolnventory was created to extend the functionally of the ArcGIS Viewer for Flex to allow users to query and upload shapefiles. Customization of ArcGIS Viewer for Flex to handle data extraction and interactive querying is achieved through custom widgets based on ArcGIS API for Flex [27]. The widgets consist of portable code blocks, some of which are already built-in and available in the Viewer for further customization [27]. These tools allow end-users to build queries based upon their specific data needs. Users with no prior GIS knowledge can open ArcGIS Viewer for Flex through the Geoportal and explore the data and derive summaries for selected areas of interest.

In addition, the Geoportal was customized to allow for selected user groups and projects to upload data through the newly created Upload Local File function built within the GeoInventory widget. This functionality has the advantage of bidirectional data provision, which differs from the unidirectional or clearinghouse approach of geospatial data supply. The Upload Local File feature would allow the tool to be configured to collect information from select invitees or the general public on utilization and modification of coastal resources (e.g., coastal habitats). Thus, private or public stakeholders may contribute their own knowledge and observations to create new map data for display and descriptive analysis. This is where our tool relates to the concept of volunteer geographic information.

\subsection{Geospatial Data}

Datasets were obtained from county and state agencies. A total of twenty four datasets were obtained through a variety of sources, including Florida Geographic Database Library (FGDL) and the Florida Fish and Wildlife Conservation Commission (FFWCC). Table 1 provides an overview of the data and data sources. Using the GeoInventory tool, both GIS and non-GIS users may explore the location of various coastal features and processes (e.g., mangrove strands, sea turtle nests, benthic 
habitats, erosion-stricken areas, etc.) and open the attribute table of each layer for additional information on the attributes describing each feature. Seawalls, bulkheads, marinas and docks were digitized from high resolution orthoimagery for the north Miami-Dade area.

Table 1. Data and Data Sources

\begin{tabular}{|c|c|c|c|c|}
\hline & Title & Feature Class & Summary & Year \\
\hline \multirow{13}{*}{ 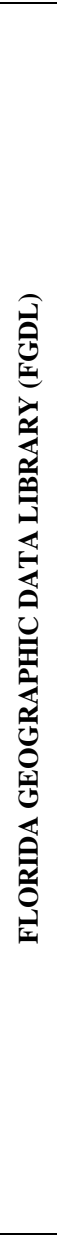 } & $\begin{array}{l}\text { BATHYMETRIC CONTOURS FOR THE STATE } \\
\text { OF FLORIDA AND SURROUNDING AREAS }\end{array}$ & Line & $\begin{array}{c}\text { Bathymetric contours with } \\
\text { increasing resolution in coastal areas }\end{array}$ & 2000 \\
\hline & COASTAL BARRIER BOUNDARIES & Polygon & $\begin{array}{c}\text { Florida coastal counties vulnerable } \\
\text { to coastal erosion and inundation from } \\
\text { sea level rise or storm surge } \\
\end{array}$ & 2002 \\
\hline & COASTAL BARRIER RESOURCES SYSTEM & Polygon & Coastal Barrier Resources System Boundaries & 2011 \\
\hline & CRITICAL BEACH EROSION IN FLORIDA & Line & $\begin{array}{l}\text { An inventory of Florida's erosion problem areas } \\
\text { fronting on the Atlantic Ocean and the } \\
\text { Straits of Florida, with roughly seventy } \\
\text { coastal barrier tidal inlets }\end{array}$ & 2010 \\
\hline & FISH MANAGEMENT AREAS OF FLORIDA & Polygon & $\begin{array}{c}\text { Boundaries of Fish Management Areas (FMA) } \\
\text { administered by the Florida Fish and Wildlife } \\
\text { Conservation Commission (FWC) }\end{array}$ & 2010 \\
\hline & FLORIDA MANGROVES & Polygon & Mangroves in Florida & 2010 \\
\hline & FLORIDA SEAGRASS & Polygon & Statewide seagrass data & 2010 \\
\hline & $\begin{array}{l}\text { FLORIDA UNDEVELOPED COASTAL } \\
\text { BARRIER }\end{array}$ & Polygon & $\begin{array}{c}\text { Areas in Florida designated as undeveloped } \\
\text { coastal barriers in accordance with the Coastal } \\
\text { Barrier Resources Act }\end{array}$ & 2008 \\
\hline & $\begin{array}{l}\text { FLORIDA'S ENVIRONMENTALLY } \\
\text { SENSITIVE SHORELINES }\end{array}$ & Line & $\begin{array}{l}\text { Locations and descriptions of Florida's } \\
\text { environmentally sensitive shorelines }\end{array}$ & 2003 \\
\hline & SOUTH FLORIDA BENTHIC HABITATS & Polygon & $\begin{array}{l}\text { Benthic data for Florida Bay, Biscayne Bay and } \\
\text { the Florida Keys National Marine Sanctuary }\end{array}$ & 2001 \\
\hline & $\begin{array}{l}\text { THREATS TO FLORIDA'S } \\
\text { FRESHWATER HABITATS }\end{array}$ & Polygon & $\begin{array}{l}\text { Representing threats to } \\
\text { Florida's freshwater habitats }\end{array}$ & 2008 \\
\hline & WETLANDS INVENTORY (FLORIDA) & Polygon & $\begin{array}{l}\text { Extent, approximate location and type of } \\
\text { wetlands and deepwater habitats }\end{array}$ & 2011 \\
\hline & $\begin{array}{l}\text { WILDLIFE OCCURRENCE } \\
\text { DATABASE (1894-2006) }\end{array}$ & Point & $\begin{array}{l}\text { Database provides a standardized format for } \\
\text { recording and managing incidental, casual, } \\
\text { or short-term systematic observations of wildlife }\end{array}$ & 2006 \\
\hline \multirow{11}{*}{ 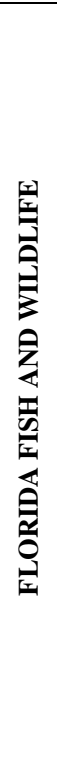 } & ARTIFICIAL REEFS (FLORIDA) & Point & Artificial reef deployments & 2011 \\
\hline & $\begin{array}{c}\text { FLORIDA CORAL AND } \\
\text { HARD BOTTOM HABITATS }\end{array}$ & Polygon & Represents coral and other hard bottom type & 2009 \\
\hline & $\begin{array}{l}\text { FLORIDA PUBLIC ACCESS } \\
\text { BOAT RAMP INVENTORY }\end{array}$ & Point & $\begin{array}{c}\text { Descriptive inventory of public } \\
\text { access boat ramps throughout Florida }\end{array}$ & 2008 \\
\hline & FLORIDA SALTWATER MARSH & Polygon & Represents the saltwater marsh areas in Florida & 2010 \\
\hline & FLORIDA SHORELINE & Polygon & Florida Shoreline 1:12,000 & 2004 \\
\hline & FLORIDA TIDAL FLATS & Polygon & $\begin{array}{l}\text { Non-vegetated areas of sand or mud protected } \\
\text { from wave action and composed primarily of mud } \\
\text { transported by tidal channels }\end{array}$ & 2009 \\
\hline & $\begin{array}{c}\text { INTRACOASTAL WATERWAY } \\
\text { EAST COAST (FLORIDA) } \\
\end{array}$ & Polygon & Represents east coast Intracoastal Waterway & 1996 \\
\hline & $\begin{array}{c}\text { MANATEE SYNOPTIC } \\
\text { SURVEY SIGHTINGS (1991-2011) }\end{array}$ & Point & A general count of manatees statewide & 2011 \\
\hline & MANGROVES (FLORIDA) & Polygon & Dataset represents mangroves in Florida & 2009 \\
\hline & MARINE FACILITIES (FLORIDA) & Point & Locations of marine facilities around Florida & 2001 \\
\hline & SEA TURTLE NESTING BEACHES (FLORIDA) & Line & $\begin{array}{l}\text { Total distribution, seasonality and } \\
\text { abundance of nesting by sea turtles in Florida }\end{array}$ & 2010 \\
\hline
\end{tabular}


In addition, we intersected selected layers in Table 1 to create a vector grid with a resolution of $100 \mathrm{~m} \times 100 \mathrm{~m}$. Data processing was carried out using the geoprocessing tools in ESRI's ArcMap and ArcCatalog and re-projected to a common coordinate system (Albers Conical Equal Area). The attribute table of the grid includes information on level of urbanization, coastal protection measures, substrate, bank condition, bathymetry, beach presence, marsh presence, vegetation, turtle nesting sites, mangrove strands, etc. This database can be queried for important information to provide the user with rapid summary reports useful to proactively consider future coastline development and assess the regional cumulative effect of lost connectivity between the coast and reef and offshore marine ecosystems. For example, a user can select several cells from the grid and generate a summary report with information on various attributes, such as dominant vegetation species, average bathymetry, presence/absence of sea turtle nesting sites, etc. The tool may also help identify and classify management options for high-medium and low-energy wave shorelines or evaluate management options and provide science-based policy recommendations, including the viability of living shoreline treatments.

The resulting shoreline inventory and characterization geodatabase enables the derivation of quick summary reports for user-selected areas. The vector grid database format enables users to quickly derive site-specific (e.g., each grid cell), as well as regional assessments. Metadata files store information about the data source of origin, standards and data quality, ownership and copyright (if applicable), data scale, date/year of publication and explanation of the attribute acronyms as displayed in the attribute table. Web links to the metadata files provided by the originator/publisher of the secondary data is accessible through the geoportal. The Content Standard for Digital Geospatial Metadata (CSDGM), FGDC-STD-001-1998, version 2.0 and the North American Profile (NAP) of ISO 19115 published by the Federal Geographic Data Committee (FGDC) (http://www.fgdc.gov) will guide the development and storage of geographic metadata for the newly created datasets, such as digitized seawalls, bulkheads and other structural shoreline stabilization options. Field evaluations will be conducted in the future to collect information on the current "state" of the shoreline and attributes, such as shoreline bank condition, structure type, structure condition, slope of the bank and presence/absence of emergent and submerged plant species and communities. This field data in addition to information from reports and property owners will be added to the GIS database. The creation of additional metadata for geospatial datasets resulting from field evaluation of existing "soft" armoring approaches will follow the general standards of the Metadata Profile for Shoreline Data developed by FGDC in collaboration with NOAA Coastal Services Center, which contains a standardized set of "terms and data elements required to support metadata for shoreline and coastal data sets" [28] (p. 3).

\subsection{A Discussion Forum and General User Information Blog}

The proposed tool will also facilitate map-based discussion forums and creation of user groups to encourage citizen participation in decisions regarding shoreline stabilization and restoration. The project team is currently investigating the development of a web-based discussion forum with access to the customized Geoportal so that users can set groups, examine the datasets, conduct queries and initiate discussion with regard to shoreline uses and stabilization options. O'Dea et al. [2] (p. 611) asserts that "additional relevant information adds value to the map display by helping to highlight 
specific coastal topics". Additionally, a General User Information Blog will host mash-ups, maps and geotagged pictures and information sheets to facilitate discussions of relevant coastal issues.

\section{Results and Discussion}

The results section is organized to address three aspects of the shoreline inventory and characterization tool currently under development. These include: (1) technical details on the customization with examples of modified programming codes; (2) description of the query widgets and the functions they perform; and (3) feedback from presentations and a demo session and discussion of the applicability of the tool with specific examples of how the functions can be used.

\subsection{Customization of ESRI Geoportal Webserver Components: Technical Details}

Technical details of the customization process provided in this section are organized by components displayed in Figure 3. The Geoportal Server is currently hosted on a dedicated machine/ server with a static IP at the FAU Visual Planning Technology Lab (www.vptlab.fau).

Web Application File Organization: During the installation process, the Apache Tomcat web server initializes the web application geoportal.war to create eight (8) subfolders (Figure 3), including those that store widgets, JavaServer Pages (JSP) files, Catalog Service for the Web, geoportal search widgets for HTML, Flex and Silverlight.

User Interface Components: Based on JavaServer Faces (JSF) framework, these components manage how the website pages are processed, routed and executed. This software component is customized by modifying the configuration rules in the <Apache Software Foundation path> Tomcat 7.0 webapps\geoporta৯WEB-INF\gpt-faces-config.xml file.

Identity Components (Lightweight Directory Access Protocol and Single Sign-On) is a Java-based identity store configured to contain and process information about users and groups. A sample code is provided below:

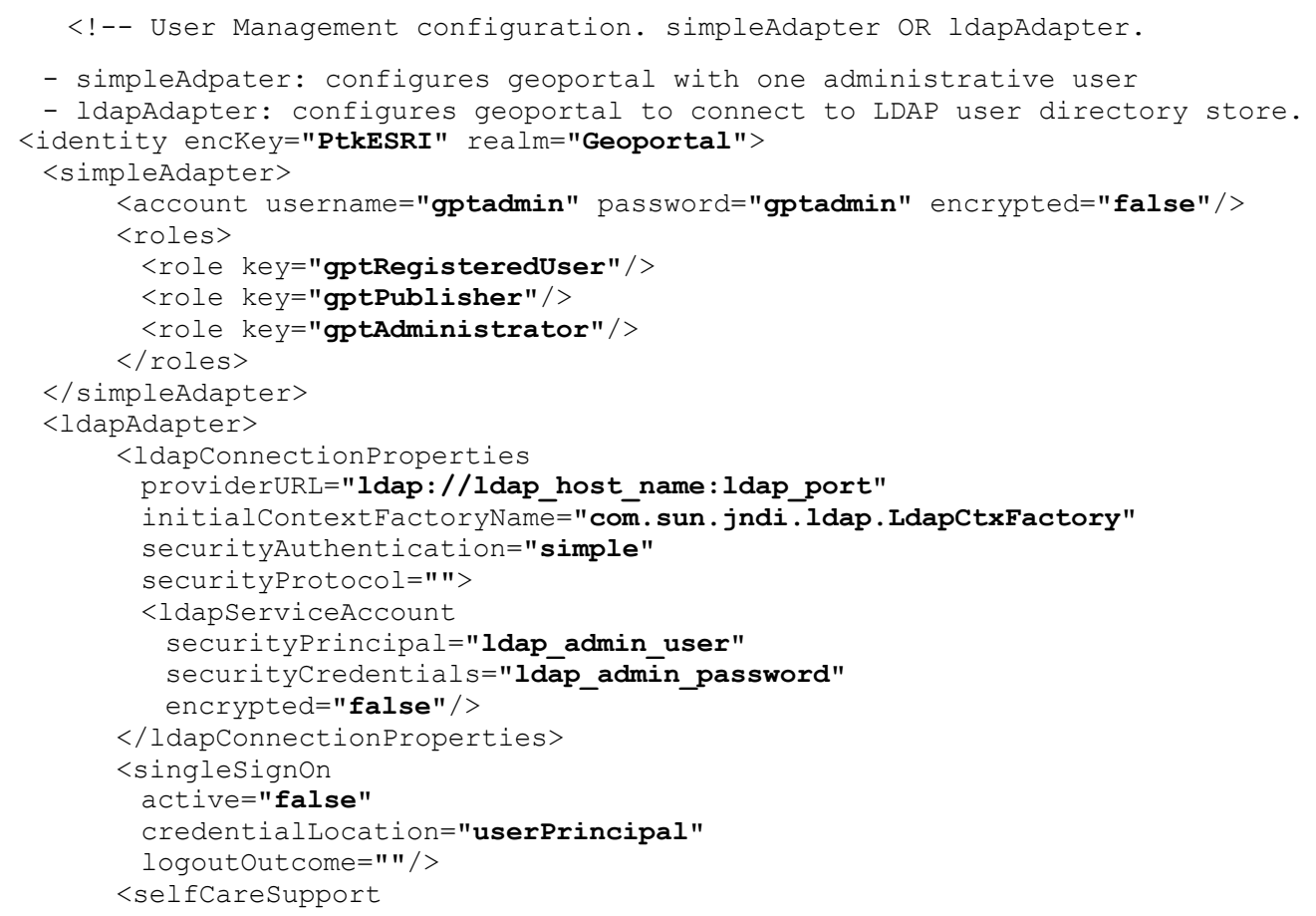




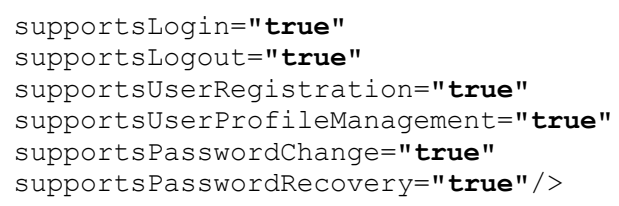

The identity components are used to set three different levels of access based on Geoportal group memberships: (1) administrator has full access and the ability to approve metadata documents; (2) publisher who is able to publish metadata documents and register remote sites; (3) registered user who is able to save a history of searches and maps for later use. The following code provides details on user authentication patterns:

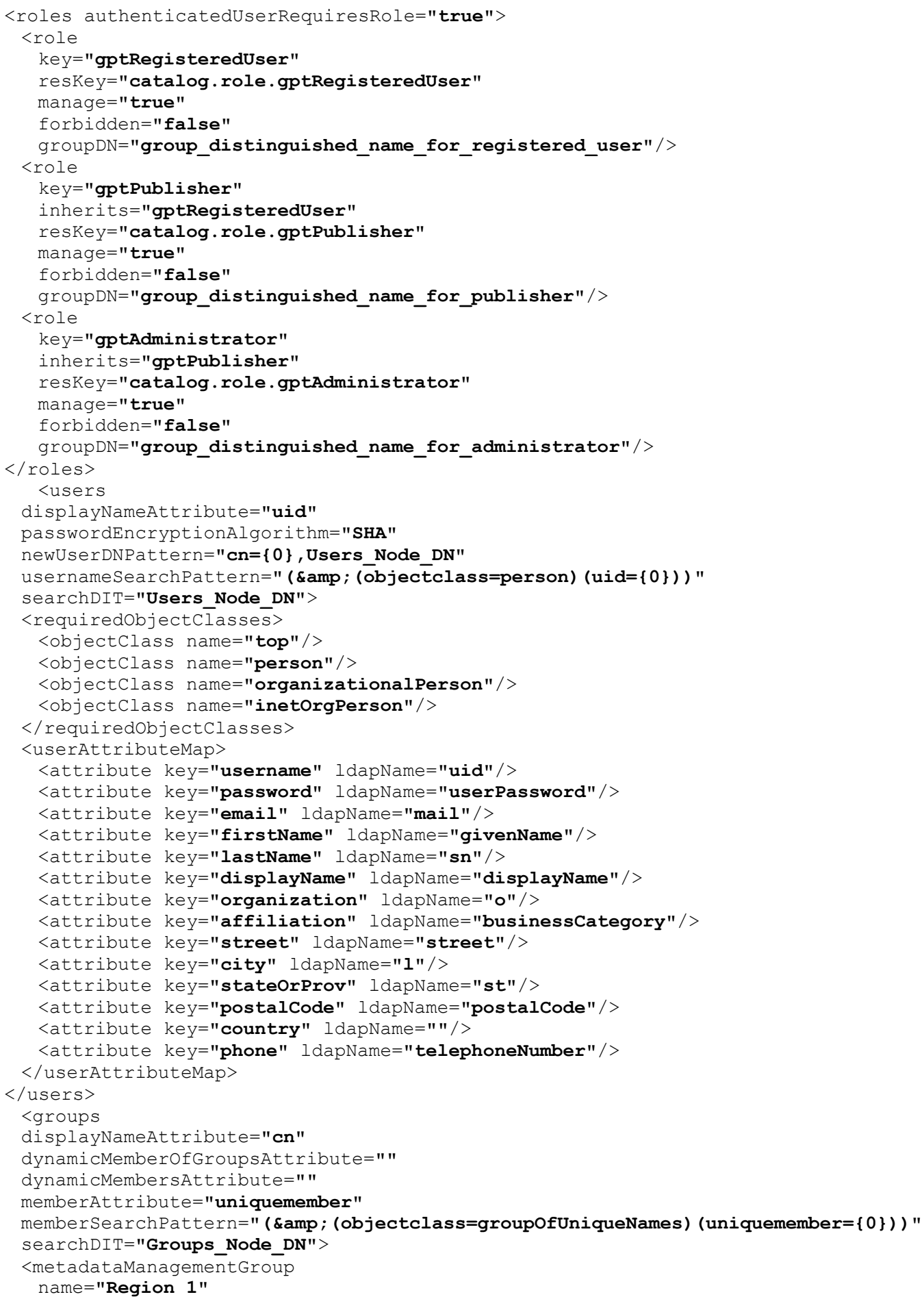




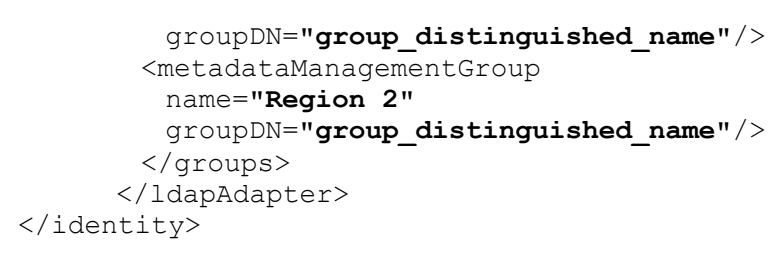

The user and group attributes and passwords were configured in the <Apache Software Foundation

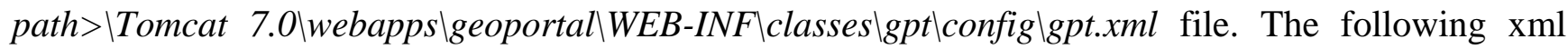
data segment illustrates how the administrator name and password is specified:

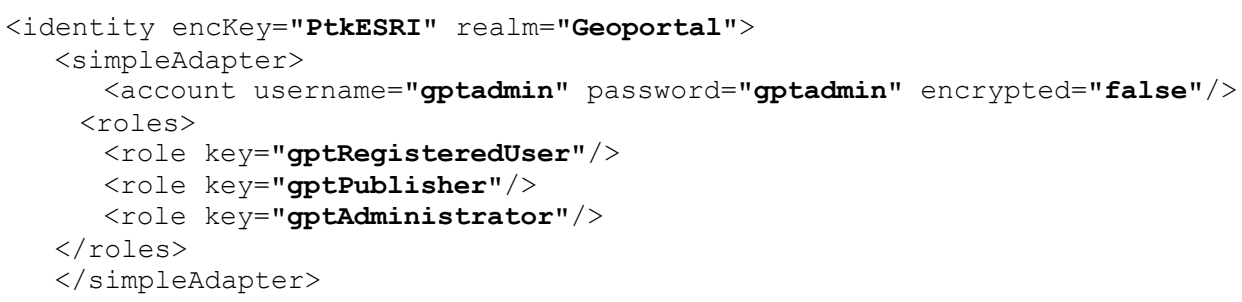

The Geoportal XML Editor (GXE): Provides advanced metadata editing capabilities for several formats; however, for the purposes of this project, the metafile in FGDC format was generated to point to the location of the shapefiles. For this project, the geoportal installation instructions specified the use of the Postgre SQL database system as part of its publication components. Oracle and SQL Server databases are also supported.

ArcGIS Viewer for Flex: Allows users to create and deploy a custom GIS web mapping application that supports: (i) data display and extraction; (ii) interactive querying; (iii) web editing; (iv) geocoding; and (v) printing. Functionality in the ArcGIS Viewer for Flex is based on an extensible widget programming model that contains portable code blocks, which provide functionality in the viewer in a modular fashion and may be easily added or removed from the viewer.

Database Tables: For this project, the geoportal installation instructions provided scripts to generate the database tables for the Postgre SQL database. The tables are stored in a relational database management system. Catalog Service: The catalog service, which utilizes Catalog Service for the Web (CS-W) 2.0.2 interface specification, allows publication of metafiles that point to the shapefiles that are published in the geoportal server. For example "Bathym_Clipped_WGS.xml" points to the "bathym" shapefile, which are the bathymetric contours for the State of Florida and surrounding areas (Table 1). Search Components: For this project, the GeoInventory widget utilized a REST Query API call to retrieve the shapefiles from the geoportal server and return the results in GeoRSS format. KML, ATOM, JSON, CSV and HTML formats are also supported. Client services, including browsers and Google Earth, can generate and parse these formats and utilize the REST Query API service endpoint. Preview Function: Provides a map view of live data described by metadata records in the geoportal. The Preview function may be launched from the following: (1) search result page from the Preview link; (2) through the web browser URL window; (3) from an embedded URL in another web page. The Preview function may also be triggered by the search result Details page, displaying if the metadata describes a live data resource. 


\subsection{Queries Functions}

The overall project goal centered around shoreline adaptation to changing environmental conditions and related challenges that emanate from a lack of simple viable means to identify and classify priorities for shoreline planning in the face of a number of coastal hazards, including sea-level rise.

Although still under development, the customized ESRI Geoportal Server helps fill this gap and has the potential to provide geospatial information to a wide range of stakeholders, including state, county and local agencies; coastal planners, managers and engineers involved with shore zone management and regulation.

Figure 4. Programming code customization to support the GeoInventory widget.

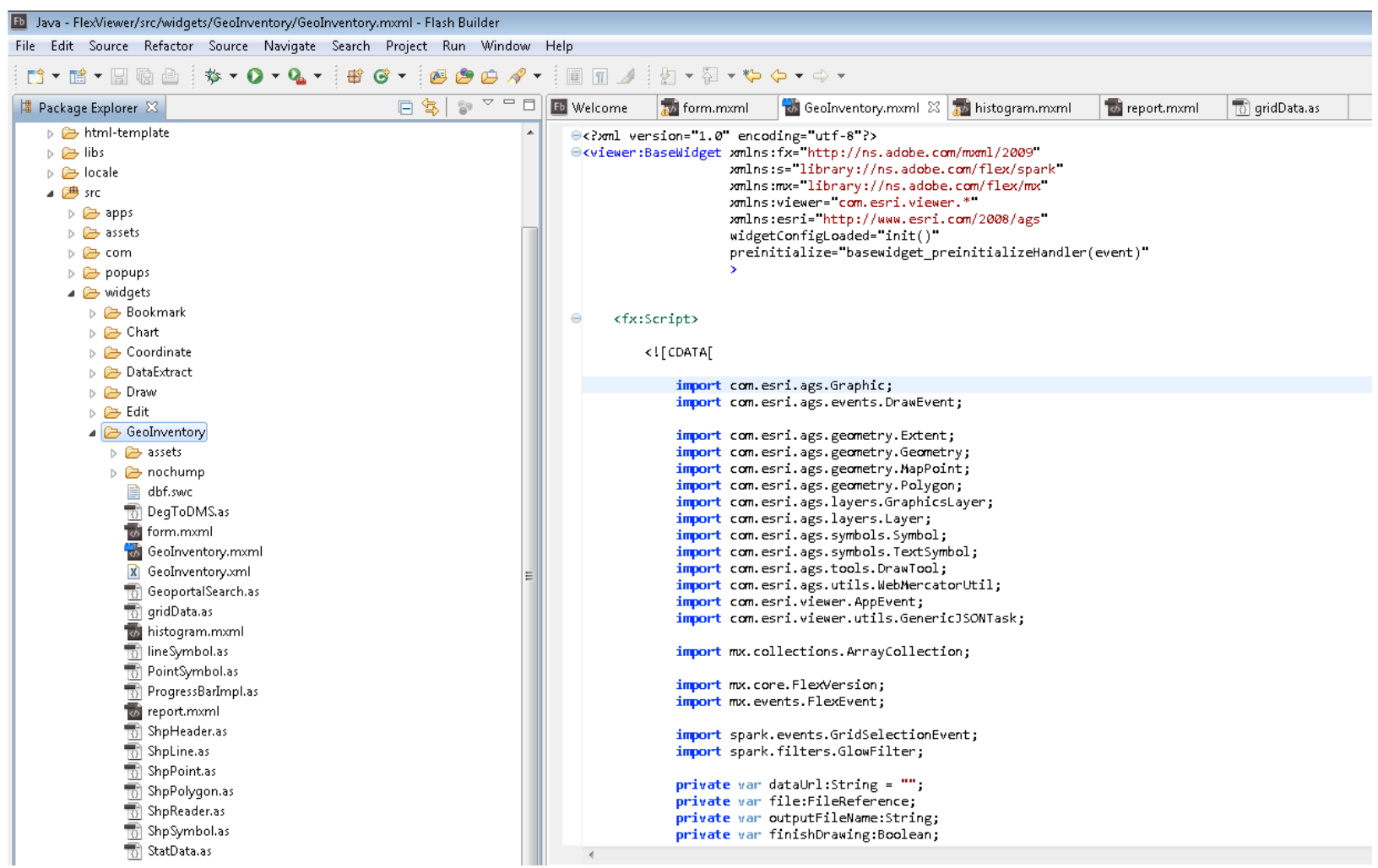

The functionally of the ArcGIS Viewer for Flex was extended by creating a customized GeoInventory widget to allow users to query and upload shapefiles. The Geoportal web application file organization stores the CS-W service definition information and contains the ArcGIS Viewer for Flex mapping application with capabilities for search and display of geographical data. The GeoInventory widget parses shoreline data stored in ESRI shapefile format. The original shapefiles must be re-projected to WGS_1984 geographic coordinate system and stored in a single zip file before they are processed by the GeoInventory widget tool. Using the GeoInventory widget, the zipped shapefile data is retrieved and uploaded. The widget allows uploads from (a) search results in the internal database described in a Metafile created by invoking the Geoportal XML Editor (GXE) software module; and (2) user-generated content in a zipped shapefile format. The GeoInventory widget tool displays the geometrical location data to the map viewer. In addition, portable code blocks were reused based on shapefile code. The following code was developed for this project: GeoInventory/GeoInventory.mxml; 
GeoInventory/Form.mxml; GeoInventory/Histogram.mxml; GeoInventory/Report.mxml; GeoInventory/ProgressBarImpl.as; GeoInventory/GeoportalSearch.as; GeoInventory/gridData.as; GeoInventory/StatData.as. For this project, the geoInventory widget (exported from Adobe Flashbuilder as GeoInventory.swf) was added in <Apache Software Foundation path>\Tomcat

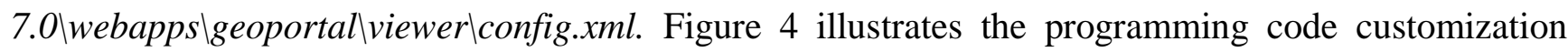
process for the GeoInventory widget.

The following JAVA and xml code segments illustrate how the GeoInventory widget was added in the viewer:

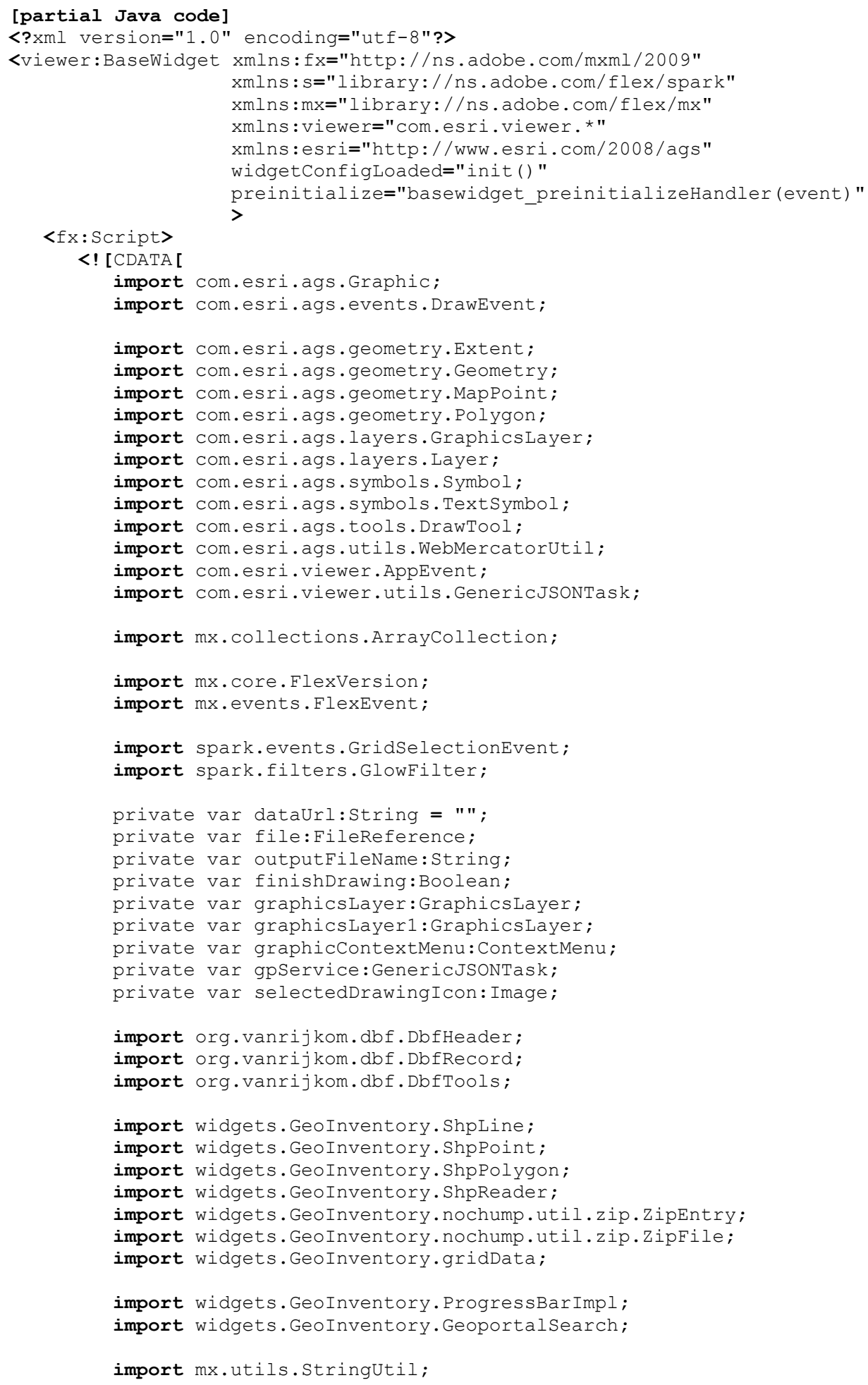




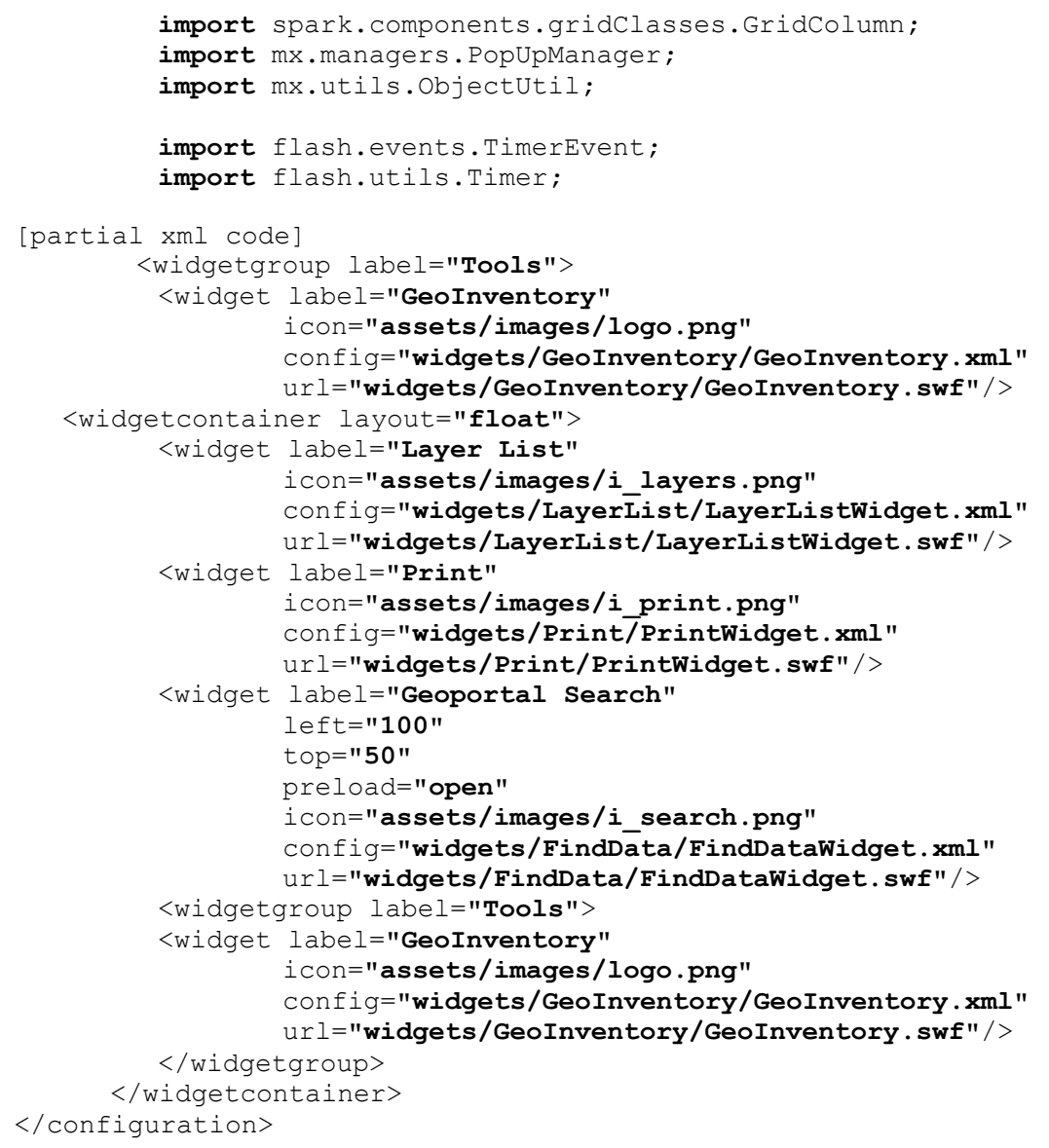

\subsection{Discussion}

Initial assessment of the tool was conducted through a Webex demonstration attended by representatives of the Nature Conservancy and the Florida Sea Grant Outreach coordinator. In addition, the project was presented at the Florida Academy of Sciences annual meeting (8-9 March 2013), which was attended by representatives of county and local governments and academia. Questions centered on issues of public data access, administrative privileges, user groups and disclaimers built within the application. As a result of these preliminary discussions, we modified the access setup for the application, including Geoportal administrator, data publisher and registered user. A future goal of the application would allow the creation of user groups to allow "tiered" access to the information in the application. Specific user logins would be assigned to each type of user, and access would only be granted to certain features in the application based on that login. The comments suggest that overall the tool has the potential to improve the general web user understanding of the factors that shape coastal environments, including landform characteristics, topography, nearshore bathymetry, wave action, substrate, vegetation and type of development. Hence, it can be useful in promoting knowledge about the shoreline capacity to withstand the damaging effects of changing conditions. In addition, it was acknowledged that a map service combined with information blogs and discussion forums, can engage a wide variety of stakeholders in a dialog about future placement of urban development and selection of appropriate shoreline stabilization options.

Figure 5 displays an example query of sample data from the pilot study that focused on the North Miami Dade county study area. Descriptive statistics (e.g., sum, average, standard deviation) may be generated for an entire column from the attribute table or for selected areas, as shown on Figure 5, by 
clicking the Report button. That widget tool was created in Adobe Flash Builder. As Figure 6 indicates, a user may perform queries by drawing a rectangle (blue box, Figure 6) on the map viewer and retrieve attribute information associated with the geographical location in the selected area by double clicking on the layer. Currently, the user needs to be familiar with the details of the attribute information in the shapefile in order to understand the analyzed data. Future customization will enable users who are not familiar with the attributes in the shapefile to view a pop-up screen with a description of the metadata related to a specific attribute. The documentation for every attribute contained in the shapefile may be described in a metafile stored in the internal database. To speed up attribute display, the Geo Inventory widget will be customized to parse the metafile or the additional documentation file and, thereby, display documentation for every attribute.

Figure 5. A query of sample data.

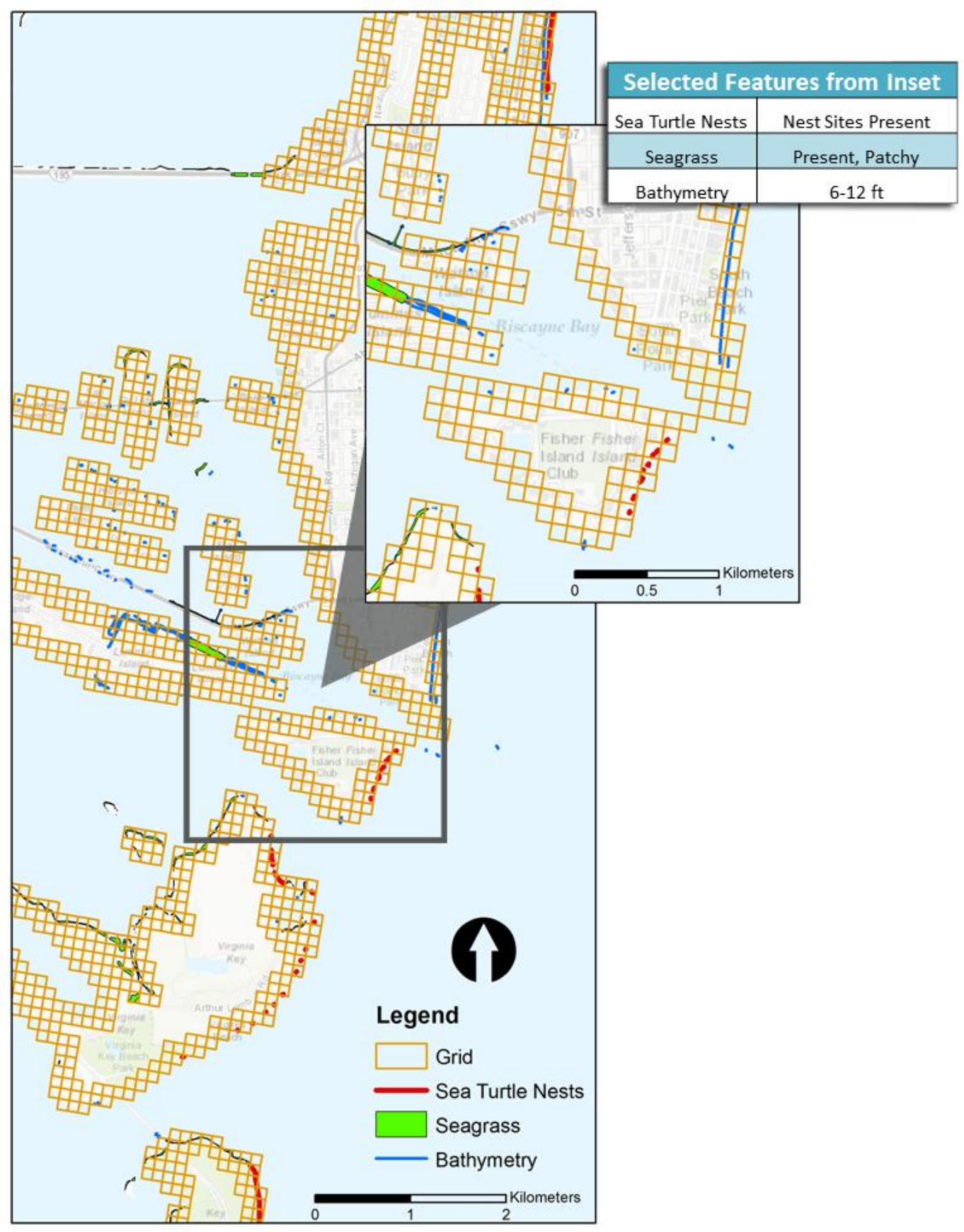


Figure 6. A user may select and compare the attributes of several areas simultaneously.

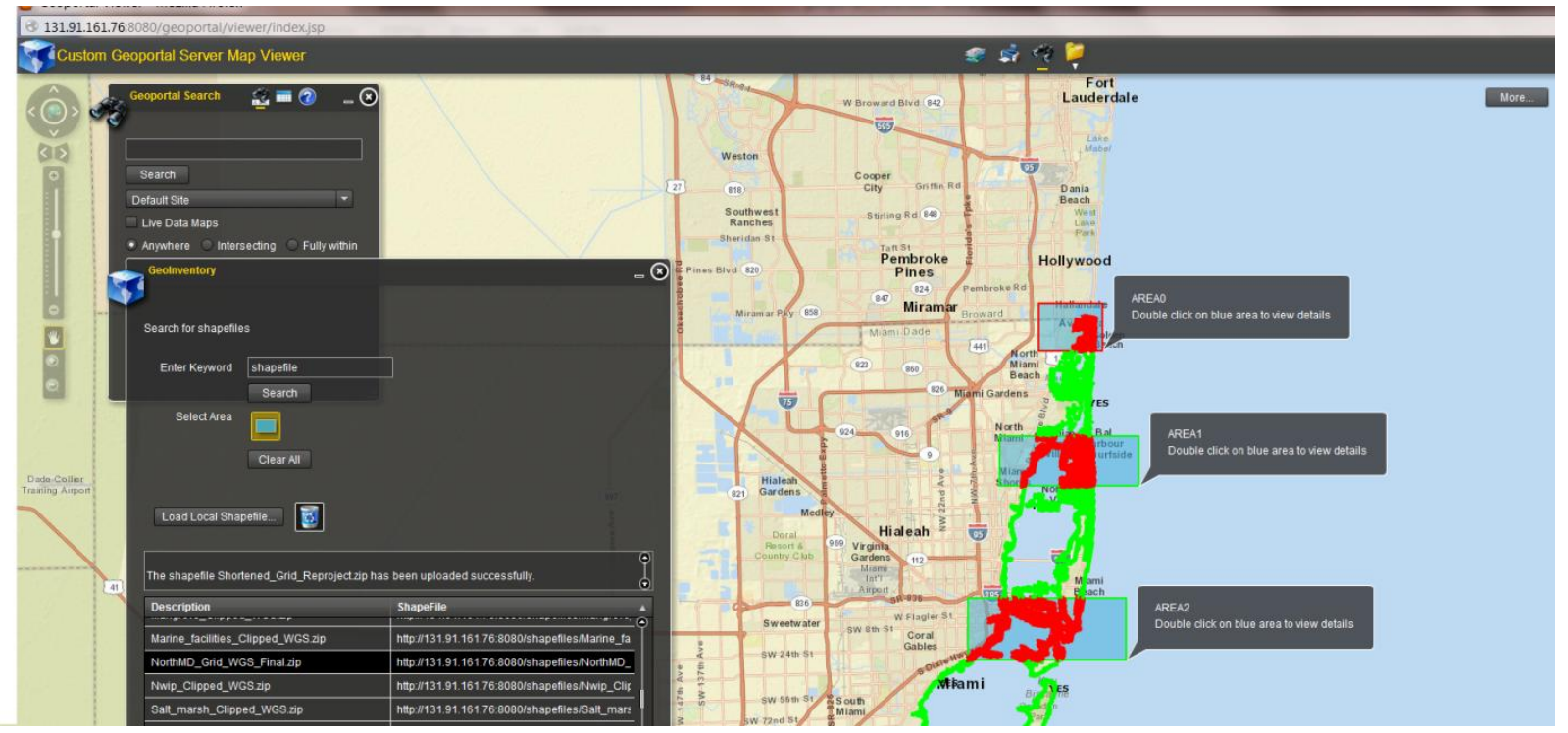

Mapping and visualizing biophysical data along with human-induced modifications of the shoreline, such as hardened structures (e.g., seawalls, bulkheads, jetties, revetments and groins commonly used to protect our coasts in areas of high wave energy impact), could potentially increase awareness of how these structures impact coastal resources, affect sediment sources along the shore and sediment transport, alter water and habitat quality of the adjacent subaqueous land and change ecosystem productivity [29]. The tool can also be used to promote "soft" stabilization techniques as viable options that ensure comparable protection under suitable landscape and environmental conditions. Enhancing unconsolidated shorelines with mangroves, planting wetlands vegetation, removing exotic species, dune creation and building lime-rock protection barriers where appropriate are viable non-structural alternatives to the often preferred to seawalls and ripraps. The soft armoring approach requires a wealth of knowledge regarding the extent of the intertidal zone, fetch, bathymetry, presence of seagrass and other subaqueous vegetation, knowledge about species-specific elevation grades, location where fill needs to be removed and flushing channels need to be created. Decisions regarding future development in the shore zone require collaborative regional planning and the development of this tool aims at facilitating these efforts.

\section{Conclusions}

Sustainable approaches to coastal development are inherently complicated by the complex land use patterns of coastal areas and their embedded shorelines, as well as ongoing challenges presented by erosion, habitat destruction and sea level rise [25]. Competing policies in development, habitat conservation, flood hazard mitigation and shoreline protection and the multitude of stakeholders add to that complexity and highlight the need for geospatial data and tools to facilitate discussion and decision-making of appropriate management and regulatory strategies [30].

Against this backdrop, this article featured a collaborative research effort to build upon exciting efforts by government agencies, educational institutions, research institutes and private firms to design and develop interactive coastal atlases and coastal planning web-based tools that provide opportunities 
for spatial data exploration and simultaneously allow for user input, participation and comparison of user-proposed solutions against scientific criteria [7]. Specifically, researchers from urban planning and computer science collaborated to develop a geospatial shoreline inventory tool that incorporates a sample database with twenty-four datasets representing physical, geomorphological, geological and biological conditions and features along the coastline, as well as visualization and analytical capabilities. Beyond the availability of data was the need to develop tools that allow for identification, classification and communication of priorities for coastal development, especially for coastal residents and property owners [25,31]. The ESRI Geoportal Server was customized by adding a GeoInventory Tool capability that allowed the data to be searched, displayed and analyzed on a map viewer.

The tool is fully functional and allows for database queries and generation of rapid summary reports when the user selects any number of cells from the grid. It is our intent that additional refinements will allow the tool to be used to facilitate map-based discussion forums and creation of user groups to encourage citizen participation in decisions regarding shoreline stabilization and restoration and promotion of sustainable coastal development.

The pilot study also revealed insights with regard to interdisciplinary project collaboration involving researchers from urban planning and computer science. Initially, the urban planners (both faculty and students) considered themselves as merely "content providers", while the computer engineers were focused on programming tasks. The team members with urban planning backgrounds were relying on their knowledge of the GIS functionality (i.e., file formats, layouts, outputs, etc.) and applications in the context of shoreline management, while the computer science students were focused on applying their skills in software development. The exchange of knowledge and ideas eventually led to better understanding from both sides of opportunities and challenges. Both urban planners and computer engineers enriched their interdisciplinary knowledge, which generated new ideas for future collaboration, such as Android App development.

\section{Acknowledgments}

This research would not have been possible without funding from the FAU Climate Change Initiative Seed Grant aimed at providing initial support for pilot projects and small studies. We also wish to acknowledge Marta Viciedo, who assisted with data collection in the initial phases of this pilot project.

\section{Conflict of Interest}

The authors declare no conflict of interest.

\section{References}

1. Goodchild, M.F.; Fu, P.; Rich, P. Sharing geographic information: An assessment of the geospatial one-stop. Ann. Assn. Amer. Geogr. 2007, 97, 250-266.

2. O'Dea, E.; Dwyer, E.; Cummins, V.; Wright, D. Potentials and limitations of Coastal Web Atlases. J. Coast. Conserv. 2011, 15, 607-627. 
3. Environmental Systems Research Institute (ESRI). Geoportal Server. Available online: http://www.esri.com/software/arcgis/geoportal/live-user-sites (accessed on 3 February 2013).

4. Sieber, R.E.; Rahemtulla, H. Model of Public Participation on the Geoweb. In Proceedings of GIScience 2010, 6th International Conference on Geographic Information Science, Zurich, Switzerland, 14-17 September 2010. Available online: http://www.giscience2010.org/pdfs/ paper_240.pdf (accessed on 5 February 2013).

5. Craglia, M.; Goodchild, M.F.; Annoni, A.; Camara, G.; Gould, M.; Kuhn, W.; Mark, D.; Masser, I.; Maguire, D.; Liang, S.; et al. Next-generation digital earth: A position paper from the vespucci initiative for the advancement of geographic information science. Int. J. Spat. Data Infrastr. Res. 2008, 3, 146-167.

6. Mossbauer, M.; Schernewski, G.; Bock, S. The effectiveness of coastal web portals-A critical analysis. J. Coast. Conserv. 2012, 16, 439-448.

7. McClintock, W. Designing for Our Oceans. In Proceedings of the 2012 GeoDesign Summit, Redlands, CA, USA, 5 January 2012. Available online: http://video.esri.com/watch/1002/ designing-for-our-oceans (accessed on 6 June 2012).

8. Ferreira, M.A.; Soares, L.; Andrade, F. Educating citizens about their coastal environments: Beach profiling in the Coastwatch project. J. Coast. Conserv. 2012, 16, 567-574.

9. Vasconcelos, L.; Caser, U.; Pereira, M.J.R.; Concalves, G.; Sa, R. MARGOV—Building social sustainability. J. Coast. Conserv. 2012, 16, 523-530.

10. Goodchild, M.F.; Glennon, J.A. Crowdsourcing geographic information for disaster response: A research frontier. Intl. J. Digit. Earth 2010, 3, 231-241.

11. Manfré, L.A.; Hirata, E.; Silva, J.B.; Shinohara, E.J.; Giannotti, M.A.; Larocca A.P.C.; Quintanilha, J.A. An analysis of geospatial technologies for risk and natural disaster management. ISPRS Int. J. Geo-Inf. 2013, 2, 166-185.

12. Rodriguez, I.; Montoya, I.; Sanchez, M.J.; Carreno, F. Geographic information systems applied to integrated coastal zone management. Geomorphology 2009, 107, 100-105.

13. Souto, H.; Gomes, N.; Carvalho, R. Development of a GIS for the "Celebration of Coastal Culture". J. Coast. Conserv. 2012, 16, 431-437.

14. Janeiro, J.; Martins, F.; Relvas, P. Towards the development of an operational tool for oil spills management in the Algarve coast. J. Coast. Conserv. 2012, 16, 449-460.

15. Root-Bernstein, M.; Rosas, N.A.; Osman, L.P.; Ladle, R.J. Design solutions to coastal human-wildlife conflicts. J. Coast. Conserv. 2012, 16, 585-596.

16. Rinner, C.; Kessler, C.; Andrulis, S. The use of Web 2.0 concepts to support deliberation in spatial decision-making. Comput. Environ. Urban Syst. 2008, 32, 386-395.

17. Goodchild, M.F. Citizens as voluntary sensors: Spatial Data Infrastructure in the World of Web 2.0. Int. J. Spat. Data Infrastr. Res. 2007, 2, 24-32.

18. Goodchild, M.F. Citizens as sensors: The world of volunteered geography. GeoJournal 2007, 69, 211-221.

19. Scharl, A.; Tochtermann, K. The Geospatial Web: How Geobrowsers, Social Software and the Web 2.0 are Shaping the Network Society; Springer: London, UK, 2007.

20. Environmental Systems Research Institute (ESRI). Geoportal Server: Key Features. Available online: http://www.esri.com/software/arcgis/geoportal/key-features (accessed on 11 February 2013). 
21. Mitsova, D.; Esnard, A.M.; Li, Y. Using enhanced dasymetric mapping techniques to improve the spatial accuracy of sea level rise vulnerability assessments. J. Coast. Conserv. 2012, 16, 355-372.

22. Milano, G. Restoration of coastal wetlands in southeastern Florida. Wetland J. 1999, 11, 15-24.

23. Mitsova, D.; Vos, J.; Gardinali, P.; Stafeychuk, I. Variability in road runoff pollution by Polycyclic Aromatic Hydrocarbons (PAHs) in the urbanized area adjacent to Biscayne Bay, Florida. J. Environ. Prot. 2011, 2, 1317-1330.

24. Berman, M.R.; Berquist, H.; Herman, J.; Nunez, K. The Stability of Living Shorelines-An Evaluation; Final Report to NOAA/NOAA Chesapeake Bay Program Office; Center for Coastal Resources Management, Virginia Institute of Marine Science: Gloucester Point, VA, USA, 2007.

25. Mitsova, D.; Esnard, A.-M. Holding back the sea: An overview of shore zone planning and management. J. Plan. Lit. 2012, 27, 446-459.

26. Burke D.G.; Hardaway, C.S. South River Shore Erosion Management and Living Shoreline Guidelines. Available online: http://www.burkeassociates.biz/documents/guidelines3_01_07.pdf (accessed on 10 April 2011).

27. Environmental Systems Research Institute (ESRI). ArcGIS Viewer for Flex. Available online: http://help.arcgis.com/en/webapps/flexviewer/help/index.html\# (accessed on 11 February 2013).

28. Federal Geographic Data Committee (FGDC). Shoreline Metadata and Glossary in Support of a National Shoreline Data Content Standard. Available online: http://www.fgdc.gov/standards/ projects/FGDC-standards-projects/metadata/shoreline-metadata/shore_pr.pdf (accessed on 4 April 2013).

29. Stiles, W.A. Living Shorelines: A Strategic Approach to Making It Work on the Ground in Virginia. In Proceedings of the 2006 Living Shoreline Summit, Williamsburg, VA, USA, 6-7 December 2006; pp. 99-104. Available online: http://www.dnr.state.md.us/irc/docs/00013969.pdf (accessed on 5 October 2012).

30. Brown, G. Public Participation GIS (PPGIS) for regional and environmental planning: Reflections on a decade of empirical research. URISA J. 2012, 24, 7-18.

31. Baldwin, R. NOAA Geoportal Speeds Data Discovery at National Climatic Data Center. ArcNews 2011. Available online: http://www.esri.com/news/arcnews/spring11articles/noaa-geoportalspeeds-data-discovery-at-national-climatic-data-center.html\#sthash.USvOquWf.dpuf (accessed on 23 February 2013).

(C) 2013 by the authors; licensee MDPI, Basel, Switzerland. This article is an open access article distributed under the terms and conditions of the Creative Commons Attribution license (http://creativecommons.org/licenses/by/3.0/). 